\title{
The Midland and North of England Stillbirth Study (MiNESS)
}

\author{
Jayne Platts ${ }^{1,2^{*}}$, Edwin A Mitchell ${ }^{3}$, Tomasina Stacey ${ }^{4}$, Bill L Martin ${ }^{5}$, Devender Roberts ${ }^{6}$, Lesley McCowan ${ }^{7}$ \\ and Alexander E P Heazell ${ }^{1,2}$
}

\begin{abstract}
Background: The United Kingdom has one of the highest rates of stillbirth in Europe, resulting in approximately 4,000 stillbirths every year. Potentially modifiable risk factors for late stillbirths are maternal age, obesity and smoking, but the population attributable risk associated with these risk factors is small.

Recently the Auckland Stillbirth Study reported that maternal sleep position was associated with late stillbirth. Women who did not sleep on their left side on the night before the death of the baby had double the risk compared with sleeping on other positions. The population attributable risk was 37\%. This novel observation needs to be replicated or refuted.
\end{abstract}

Methods/Design: Case control study of late singleton stillbirths without congenital abnormality. Controls are women with an ongoing singleton pregnancy, who are randomly selected from participating maternity units booking list of pregnant women, they are allocated a gestation for interview based on the distribution of gestations of stillbirths from the previous 4 years for the unit. The number of controls selected is proportional to the number of stillbirths that occurred at the hospital over the previous 4 years.

Data collection: Interviewer administered questionnaire and data extracted from medical records. Sample size: 415 cases and 830 controls. This takes into account a 30\% non-participation rate, and will detect an OR of 1.5 with a significance level of 0.05 and power of $80 \%$ for variables with a prevalence of $57 \%$, such as non-left sleeping position. Statistical analysis: Mantel-Haenszel odds ratios and unconditional logistic regression to adjust for potential confounders.

Discussion: The hypotheses to be tested here are important, biologically plausible and amenable to a public health intervention. Although this case-control study cannot prove causation, there is a striking parallel with research relating to sudden infant death syndrome, where case-control studies identified prone sleeping position as a major modifiable risk factor. Subsequently mothers were advised to sleep babies prone ("Back to Sleep" campaign), which resulted in a dramatic drop in SIDS. This study will provide robust evidence to help determine whether such a public health intervention should be considered.

Trial registration number: NCT02025530

Keywords: Stillbirth, Perinatal mortality, Perinatal death, Risk factors, Sleep position, Reduced fetal movements, Fetal growth restriction

\footnotetext{
* Correspondence: jayne.platts@cmft.nhs.uk

${ }^{1}$ Maternal and Fetal Health Research Centre, Research Floor (5th floor),

Institute of Human Development, University of Manchester, Maternal and

Fetal Health Research Centre, St Mary's Hospital, Oxford Road, Manchester

M13 9WL, UK

2Department of Obstetrics, St Mary's Hospital, Oxford Road, Manchester M13

9WL, UK

Full list of author information is available at the end of the article
}

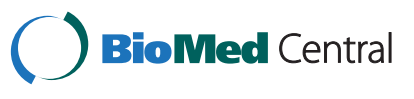

(c) 2014 Platts et al.; licensee BioMed Central Ltd. This is an Open Access article distributed under the terms of the Creative Commons Attribution License (http://creativecommons.org/licenses/by/4.0), which permits unrestricted use, distribution, and reproduction in any medium, provided the original work is properly credited. The Creative Commons Public Domain Dedication waiver (http://creativecommons.org/publicdomain/zero/1.0/) applies to the data made available in this article, unless otherwise stated. 


\section{Background}

The death of an unborn child is a tragic public health problem which currently affects approximately 2.6 million families annually worldwide [1]. Unlike other avoidable causes of maternal and child death the rate of decline of late stillbirth (at or over 28 weeks gestation) in high income countries (HICs) has slowed in recent decades [1].

The United Kingdom has one of the highest rates of stillbirth in Europe, ranking $33^{\text {rd }}$ out of 35 high-income countries [1]. The last report from the Centre for Maternal and Child Enquiries (CMACE) highlights a slow decline in the stillbirth rate in the UK from 5.4 per 1000 total births in 2000 to 5.2 per 1000 total births in 2009, [2]. This decline in stillbirth rate is supported by Gardosi [3] who attributes the reduction to the uptake of accredited training in fetal growth assessment. The Lancet Stillbirth Series [1,3,4] has highlighted the silent but prevalent public health problem of stillbirth and together with the UK Stillbirth and Neonatal Death Charity (Sands) and the Royal College of Obstetricians and Gynaecologists (RCOG) has called for research to address these unacceptably high rates.

\section{Established risk factors for late stillbirth}

Current established risk factors for late stillbirth in high income countries are well documented and have largely been identified from population-level epidemiological studies [5]. These include: advanced maternal age ( $>35$ years) [6], obesity [7], smoking [8], reduced antenatal care attendance [9], low socio-economic status [9], women from black and minority ethnic groups [2], reduced fetal movements (RFM) [10] and small for gestational age (SGA) infants [11]. A meta-analysis of population-based studies found the three most important modifiable risk factors for stillbirth were: obesity (population attributable risk (PAR) 8-18\%), advanced maternal age (population attributable risk $6-8 \%$ ) and smoking (population attributable risk 4-7\%) [5]. Of these, only cigarette smoking can realistically be addressed by women during pregnancy. Currently in the UK, there are efforts to address increased identification [3] and subsequent management of SGA infants and mothers following presentation with RFM through the implementation of guidelines $[12,13]$. To date there has been limited research investigating novel, modifiable factors which have the potential to advance knowledge and address important gaps in the field of stillbirth research.

\section{Novel modifiable factors and late stillbirth}

Although adults spend about a third of their lives asleep there had not been any studies that examined a potential relationship between maternal sleep practices and risk of late stillbirth prior to The Auckland Stillbirth Study [14]. This reported that women who did not go to sleep on their left side on the night before experiencing a late stillbirth, had a two-fold increase in risk compared with those who did go to sleep on their left [14]. This effect persisted after adjustment for confounders such as obesity. The PAR for non-left sleep position in this study was $37 \%$, greater than the PARs of obesity, advanced maternal age and smoking combined [4]. In addition, women who got up to the toilet once or less on the last night before the stillbirth, compared to those who got up more often, were also at higher risk of late stillbirth, as were those who regularly slept during the day in the last month, compared to those who did not.

The Auckland Stillbirth Study also asked women about fetal activity preceding stillbirth. In common with previous studies [15,16], a two-fold increase in late stillbirth was reported in women perceiving reduced fetal movements (RFM) [17]. Although, maternal perception of reduced fetal activity is often used to highlight pregnancies that require further investigation [18], the RCOG guideline on the management of RFM highlighted the need for further studies to understand how maternal perception of reduced fetal activity can be used in stillbirth prevention [12]. Another novel finding of Stacey et al. was the association between a single episode of vigorous fetal activity and late stillbirth [17].

In support of the findings of Stacey et al. The Sydney Stillbirth Study recruited 295 women from eight hospitals around Australia; found that women who slept on their backs were four times more likely to have a stillbirth [19]. A small survey of maternal sleep practices in Ghana also identified supine sleeping position with an increased risk of stillbirth (stillbirth rate (3/19) 15.8\% in those sleeping supine and (6/197) $3.0 \%$ in those in nonsupine position; odds ratio (OR) 8.0 ; 95\% CI 1.5-43.2) [20]. However, both these studies were underpowered to identify right sided sleep position as a risk factor and were unable to examine whether or not sleep position was a particular risk-factor for already compromised babies (FGR and RFM). The proposed study will address these issues in an ethnically and socially diverse population.

\section{Unanswered questions from the Auckland Stillbirth Study}

Publication of the Auckland Stillbirth Study and related correspondence in 2011 was accompanied by an editorial by Chappell and Smith which raised several questions [21]; the first concerned reporting bias; specifically those higher educated women would have greater access and uptake of knowledge about sleep position. This seems unlikely as this was the first published report of the association between stillbirth and sleep position. They also raised the issue of reverse causality. The association between longer sleep and not getting up at night might reflect RFM, an indication of a compromised baby, and this compromise reflects the cause of stillbirth, not duration of sleep duration or not rising at night [21]. In subsequent correspondence Frøen et al. also raised the possibility that 
the study findings are due to confounding by FGR or RFM [22]. They argued that in cases of FGR the smaller uterus might result in a reduction in the normal preference for a lateral sleeping position in late pregnancy, less bladder compression (not having to get up to the toilet as frequently), and thus better and longer sleep duration. In their reply, the Auckland Stillbirth Study team undertook additional analyses adjusting for these factors and the associations between maternal sleep practices and stillbirth did not change.

There was general agreement that before intervention studies can be planned further observational studies are necessary to confirm or refute the findings of the Auckland Stillbirth Study and investigate potential underlying mechanisms. Here, we propose a study which will achieve this in an ethnically and socially diverse population where the effects of FGR and RFM can also be studied.

\section{Hypotheses}

During this study we will test the following hypotheses:

1. Maternal left sided sleep position reduces the risk of late stillbirth.

2. Supine sleep position increases the risk of late stillbirth

3. Increased maternal sleep duration and sleeping during the day increase the risk of late stillbirth.

4. Maternal perception of RFM, prior to fetal death, increases the risk of late stillbirth.

5. Non-left sleep position, in conjunction with prolonged sleep, increases the risk of late stillbirth substantially (that is, there is an interaction between sleep position and prolonged sleep).

6. Non-left sleep position, in conjunction with a compromised baby (for example, FGR, smoke or drug exposure, RFM) increases the risk of late stillbirth.

\section{Methods/Design}

Modifiable risk factors associated with late stillbirth.

\section{Study design}

After due consideration a case control study has been selected as the most appropriate and efficient design, this methodology has been used to study relatively rare disorders such as stillbirth and addresses the aims of this study.

Alternative study designs considered by the study team included a cohort study of pregnant women. However, the size of study required is unfeasibly large; assuming a late stillbirth rate of $3 / 1,000$ births, to identify 291 cases, 97,000 women would need to be recruited at 28 weeks gestation. For a randomised controlled trial (RCT) the requisite sample size would also be prohibitively large. Assuming the absolute stillbirth rate for the non-left sided position is $3.9 / 1,000$ births and the risk is halved by left sided sleeping and that all participants are able to change their sleep position 118,000 pregnant women would be required in each group (power $=80 \%, p=0.05$ ). Asking pregnant women who normally sleep on their left to sleep in another position would be unethical as we believe this would increase their risk of stillbirth, thus only women who normally slept on the right or back could be randomised, increasing the sample size by over two fold. Therefore, it is unlikely an adequately powered RCT of individual women will ever be conducted. Importantly, this was also the case for the "back to sleep" campaign for sudden infant death syndrome which was never evaluated by RCT.

\section{Study setting}

Ethical approval has been successfully obtained from Central Manchester Research Ethics Committee (13/NW/ 0874). Participants will be recruited from a total of 35 maternity units around the Midlands and North of England. The units have been chosen for location irrespective of size or any local demographics. Recruitment to the project and administration of the questionnaire will be carried out locally by research midwives from participating units. These will be supported by three research midwife co-ordinators based in Manchester, Yorkshire and Birmingham.

\section{Time scale}

September 2013 to March 2014: Study set up, obtain ethical and research approval.

April 2014 to December 2015: Recruitment and data collection from all sites.

January 2016 to August 2016: Data analysis, report writing, dissemination of research findings.

\section{Sample size}

If the prevalence of a risk factor in the controls is between $30 \%$ and $60 \%$ (the prevalence of non-left sleep position in the Auckland Stillbirth Study was 57\%) we would need a sample of 291 cases and 582 controls to detect an odds ratio of 1.5 with a significance level of 0.05 and power of $80 \%$. This sample size would also allow us to detect an interaction with an OR of 2.5. The number of women approached to participate in the study needs to be greater than this as we anticipate a proportion of women will not participate in the study, in the Auckland Stillbirth Study this was $28 \%$. Assuming $30 \%$ non-participation rate we need to approach 415 eligible cases and 830 eligible controls.

From the data collected during the recruitment of participating units there are approximately 170 normally formed singleton stillbirths in the Greater Manchester region per year, 90 in the Mersey region, 190 in Yorkshire and 160 in the West Midlands this would give an potential annual recruitment of 610 cases. Due to the unpredictability 
of stillbirth occurrence we have allowed 18-24 months for recruitment.

\section{Inclusion criteria \\ Cases}

Women with singleton pregnancies ending in late stillbirth (with no congenital abnormality) will be recruited from participating maternity units $(\mathrm{n} \sim 35)$ in the Midlands and North of England led by four centre's in Liverpool, Manchester, Yorkshire and Birmingham.

\section{Controls}

The control group are women with an ongoing pregnancy at a group matched gestation. Women who subsequently deliver an infant with a congenital abnormality will be excluded from the study analysis. This method for control selection overcomes the limitations of previous studies which used gestation matched live birth cohorts which includes many infants who have risk factors for preterm birth.

\section{Exclusion criteria}

Women with the following criteria will not be eligible for participation in the study:

- Fetus known to have a significant congenital anomaly (as defined by the NHS fetal anomaly screening programme (FASP) - Anencephaly, Open spina bifida, Cleft lip, Diaphragmatic hernia,

Gastroschisis, Exomphalos, Serious cardiac abnormalities, Bilateral renal agenesis, Lethal skeletal dysplasia, Edward's syndrome (trisomy 18), Patau's syndrome (trisomy 13). http://fetalanomaly.screening. nhs.uk/fetalanomalyresource/whats-in-the-hexagons1/ about-the-scan/about-the-11-key-conditions)

- Multiple pregnancy

- Maternal age $<16$ years

- Women unable to give informed consent.

\section{Participant recruitment}

Prior to their discharge from their maternity unit, eligible women who have had a stillbirth (cases) will be given a brief written description of the study by their midwife or doctor and asked whether a research midwife could contact them to discuss the study. If they agree, a research midwife will contact the woman and explain the study in more detail. If the woman consents to participate, a time and place for the interview will be arranged. Interviews will be conducted by trained research midwives. The co-ordinating midwives based in Manchester, Yorkshire and Birmingham will be responsible for training local research midwives in the structured interview format and in providing an appropriate interview environment. This link will also facilitate ongoing support for local research midwives. A similar recruitment system was established through the Auckland Stillbirth Study where formal feedback from participants was positive and no negative feedback was received regarding recruitment [23]. The investigators already have experience of recruiting parents for studies after stillbirth, which will ensure potential distress is minimised. Rather than being reluctant to participate, bereaved parents are keen to participate in research, even that closely related to their time of loss [24]. We will examine the views of women regarding their participation in this research project in a small nested cohort qualitative study.

Controls will be recruited using a group matching technique, based on the previous four years birth and stillbirth figures, they will be randomly selected from the participating hospitals booking list of pregnant women (Figure 1). The control participants will be approached by their community midwife or research midwife, who will give a brief explanation of the study. If women agree to participate, a time and place for the interview will be arranged. As for the cases we will examine the views of women in the control group regarding their participation in this research project in a small qualitative nested cohort study - this will particularly focus on the impact of recruiting women with an apparently healthy pregnancy to a study about stillbirth.

\section{Data collection}

Data collection is by interviewer-administered questionnaire which has been developed from the questionnaire used in the Auckland Stillbirth Study. Participants will be interviewed face to face by research midwives with interpreters if required. For cases the interview will occur as close to the time of stillbirth as possible, usually within 1-3 weeks. We hope to reduce the interval between stillbirth and the interview from that in the Auckland Stillbirth Study. The research midwife will refer to the study's distress

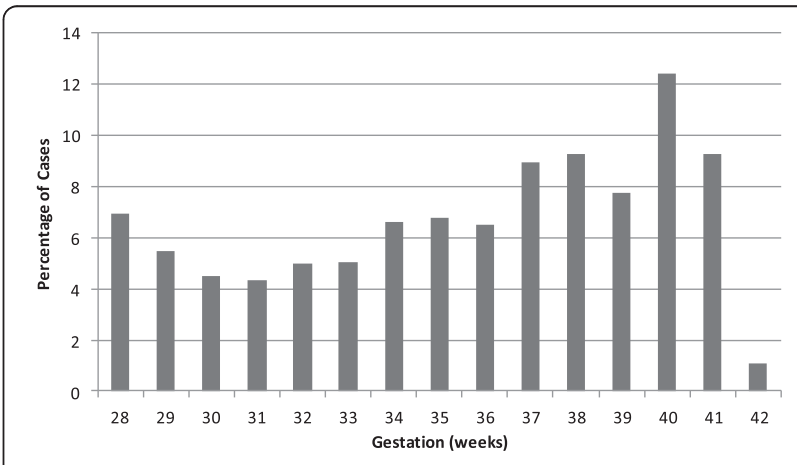

Figure 1 Distribution of gestational age of late singleton stillbirths (excluding those with congenital abnormalities) in the study units (2009-2012). Controls are group matched to these gestations. 
policy if women become upset or distressed during the interviews. Experience from Auckland and Sydney found that the questions did not increase maternal anxiety, indeed many stillbirth mothers welcomed the opportunity to talk about their experience [17].

In addition to the questionnaire, data will also be extracted from medical records. The dataset will include: demographic and socio-economic factors; maternal general health; medications; smoking; drug use (pharmaceutical and recreational); diet; body mass index (BMI) and pregnancy weight gain; fetal movements; stress assessment; sleep disordered breathing; sleep positions and other sleep habits.

\section{Analysis}

Analysis will be carried out using the standard MantelHaenszel odds ratio analysis used in case-control studies. Conditional logistic regression will be used to adjust for potential confounders (including gestation and obstetric hospital of birth) and to determine the presence of interactions, particularly to address the interaction between FGR, RFM and sleep position.

\section{Discussion}

Stillbirth is a tragic and prevalent outcome of pregnancy associated with both psychological and physical morbidity and social cost to the affected families and broader community. Stillbirth may be associated with a variety of underlying conditions. However, the terminal event is frequently not appreciated and stillbirth is likely to result from multifactorial processes [25].

The hypotheses to be tested here are important, biologically plausible and amenable to a public health intervention. In some cases, RFM is associated with evidence of placental dysfunction, which is also seen in stillbirth $[26,27]$. Non-left sided and especially supine sleep position could be associated with aorto-caval compression reducing maternal cardiac output and uterine perfusion [28]. Thus, this represents a pivotal opportunity with respect to stillbirth research. This project has the potential to:

- advance knowledge about novel, modifiable risk factors for late stillbirth, and

- translate into substantial improvements in rates of late stillbirth in the UK and internationally should the hypothesis be proved.

Current understanding of the causes and prevention of late stillbirth is similar to the state of knowledge regarding sudden infant death syndrome (SIDS) two decades ago. In the late 1980s several studies demonstrated an increased risk of SIDS when infants slept prone [29-31]. Subsequently, mothers were advised to place their babies "Back to Sleep" which resulted in a dramatic reduction in SIDS [32-35]. Similar principles may be applicable to late stillbirth; certainly any effect in stillbirth is likely to require evaluation in similar population-based intervention studies to see an effect on perinatal mortality.

It is imperative that prior to distribution of information public health interventions to reduce stillbirths are based upon robust evidence. The MiNESS will provide robust evidence which will help to determine whether such an intervention study should be considered.

\section{Abbreviations}

BMI: Body mass index; CMACE: The Centre for Maternal and Child Enquiries; Cl: Confidence interval; FGR: Fetal growth restriction; OR: Odds ratio; PAR: Population attributable risk; RCOG: Royal College of Obstetricians and Gynaecologists; RCT: Randomised controlled trial; RFM: Reduced fetal movements; Sands: The UK Stillbirth and Neonatal Death Charity; SIDS: Sudden Infant Death Syndrome; SGA: Small for gestational age.

\section{Competing interests}

None of the authors have any financial or non-financial competing interests to disclose.

\section{Authors' contributions}

$\mathrm{AH}, \mathrm{TS}, \mathrm{BM}, \mathrm{DR}, \mathrm{EM} \& \mathrm{LM}$ contributed to all aspects of the study design. AH has overall responsibility for the study. TS, EM \& LM provided study details of TASS. JP \& AH drafted the protocol and obtained ethical approvals. EM has developed the recruitment strategy and data analysis plan. JP conceptualized and developed the staff training programmes used. JP \& AH are responsible for the drafting of the manuscript. All authors gave approval for the final version of the manuscript.

\section{Acknowledgements}

The study is funded by grant GN2156 from Action Medical Research and Cure Kids and is sponsored by The University of Manchester.

The study team would like to acknowledge the hospital trusts participating in the study: Central Manchester Hospitals NHS Foundation Trust, Birmingham Women's NHS Trust, Liverpool Women's NHS Foundation Trust, Mid-Yorkshire Hospitals NHS Trust, East Lancashire Hospitals NHS Trust, University of Morecambe Bay NHS Foundation Trust, Blackpool Teaching Hospitals NHS Foundation Trust, Stockport NHS Foundation Trust, Wirral University Teaching Hospitals NHS Foundation Trust, Countess of Chester Hospitals NHS Foundation Trust, Mid Cheshire Hospitals NHS Foundation Trust, Warrington and Halton Hospitals NHS Foundation Trust, St Helens and Knowsley Teaching Hospitals NHS Trust, Southport and Ormskirk Hospitals NHS Trust, Bradford Teaching Hospitals NHS Foundation Trust, Calderdale and Huddersfield NHS Foundation Trust, Leeds Teaching Hospitals NHS Trust, South Tees Hospitals NHS Foundation Trust, Harrogate and District NHS Foundation Trust, York Teaching Hospitals NHS Foundation Trust, County Durham and Darlington NHS Foundation Trust, Worcestershire Acute Hospitals NHS Trust, University Hospitals of Coventry and Warwickshire NHS Trust, Walsall Healthcare NHS Trust, Heart of England NHS Foundation Trust, Sandwell and West Birmingham NHS Trust, The Dudley Group NHS Foundation Trust, University Hospital of North Staffordshire NHS Trust, Royal Shrewsbury Hospitals NHS Trust, Royal Wolverhampton Hospitals NHS Trust, Burton Hospitals NHS Foundation Trust, South Warwickshire NHS Foundation Trust, Sheffield Teaching Hospitals NHS Foundation Trust and Sherwood Forest Hospitals NHS Foundation Trust.

EM is supported by Cure Kids. The Maternal and Fetal Health Research Centre is supported by Tommy's - the baby charity.

Funder Reference Number: GN2156

REC Reference Number: 13/NW/0874

Sponsor Reference Number: CSP106329

\section{Author details}

${ }^{1}$ Maternal and Fetal Health Research Centre, Research Floor (5th floor), Institute of Human Development, University of Manchester, Maternal and Fetal Health Research Centre, St Mary's Hospital, Oxford Road, Manchester M13 9WL, UK. ²Department of Obstetrics, St Mary's Hospital, Oxford Road, Manchester M13 9WL, UK. ${ }^{3}$ Department of Paediatrics, University of Auckland, Private Bag 92019, Auckland 1142, New Zealand. ${ }^{4}$ Mid Yorkshire 
Hospitals NHS Trust, Dewsbury \& District Hospital, Halifax Road, Dewsbury WF13 4HS, UK. ${ }^{5}$ Birmingham Women's Hospital NHS Foundation Trust, Mindelsohn Way, Edgbaston, Birmingham B15 2TG, UK. 'Liverpool Women's Hospital NHS Foundation Trust, Crown Street, Liverpool L8 7SS, UK. ${ }^{7}$ Department of Obstetrics \& Gynaecology, University of Auckland, Private Bag 92019, Auckland 1142, New Zealand.

Received: 1 May 2014 Accepted: 12 May 2014

Published: 21 May 2014

\section{References}

1. Cousens S, Blencowe H, Stanton C, Chou D, Ahmed S, Steinhardt L, Creanga AA, Tuncalp O, Balsara ZP, Gupta S, Say L, Lawn JE: National, regional, and worldwide estimates of stillbirth rates in 2009 with trends since 1995: a systematic analysis. Lancet 2011, 377(9774):1319-1330.

2. Confidential Enquiry into Maternal and Child Health: Perinatal Mortality 2009: England, Wales and Northern Ireland. London: Centre for Enquiries into Maternal and Child Health; 2011.

3. Froen JF, Cacciatore J, McClure EM, Kuti O, Jokhio AH, Islam M, Shiffman J: Stillbirths: why they matter. Lancet 2011, 377(9774):1353-1366.

4. Flenady V, Koopmans L, Middleton P, Froen JF, Smith GC, Gibbons K, Coory M, Gordon A, Ellwood D, Mclntyre HD, Fretts R, Ezzati M: Major risk factors for stillbirth in high-income countries: a systematic review and meta-analysis. Lancet 2011, 377(9774):1331-1340.

5. Flenady V, Middleton P, Smith GC, Duke W, Erwich JJ, Khong TY, Neilson J, Ezzati M, Koopmans L, Ellwood D, Koopmans L, Ellwood D, Fretts R, Frøen JF: Stillbirths: the way forward in high-income countries. Lancet 2011, 377(9778):1703-1717.

6. Rasmussen S, Albrechtsen S, Irgens LM, Dalaker K, Maartmann-Moe H, Vlatkovic L, Markestad T: Risk factors for unexplained antepartum fetal death in Norway 1967-1998. Early Hum Dev 2003, 71(1):39-52.

7. Stephansson O, Dickman PW, Johansson A, Cnattingius S: Maternal weight, pregnancy weight gain, and the risk of antepartum stillbirth. Am J Obstet Gynecol 2001, 184(3):463-469.

8. Wisborg K, Kesmodel U, Henriksen TB, Olsen SF, Secher NJ: Exposure to tobacco smoke in utero and the risk of stillbirth and death in the first year of life. Am J Epidemiol 2001, 154(4):322-327.

9. Huang DY, Usher RH, Kramer MS, Yang H, Morin L, Fretts RC: Determinants of unexplained antepartum fetal deaths. Obstet Gynecol 2000, 95(2):215-221.

10. Froen JF, Heazell AE, Tveit JV, Saastad E, Fretts RC, Flenady V: Fetal movement assessment. Semin Perinatol 2008, 32(4):243-246.

11. Cnattingius S, Haglund B, Kramer MS: Differences in late fetal death rates in association with determinants of small for gestational age fetuses: population based cohort study. BMJ 1998, 316(7143):1483-1487.

12. Royal College of Obstetricians and Gynaecologists: Management of Reduced Fetal Movements. London: RCOG; 2011.

13. Royal College of Obstetricians and Gynaecologists: The Investigation And Management Of The Small-For-Gestational-Age Fetus. London: RCOG; 2013.

14. Stacey T, Thompson JM, Mitchell EA, Ekeroma AJ, Zuccollo JM, McCowan LM: Association between maternal sleep practices and risk of late stillbirth: a case-control study. BMJ 2011, 342:d3403.

15. O'Sullivan O, Stephen G, Martindale EA, Heazell AE: Predicting poor perinatal outcome in women who present with decreased fetal movements - a preliminary study. J Obstet Gynaecol 2009, 29(8):705-710.

16. Heazell AE, Froen JF: Methods of fetal movement counting and the detection of fetal compromise. J Obstet Gynaecol 2008, 28(2):147-154.

17. Stacey T, Thompson JM, Mitchell EA, Ekeroma A, Zuccollo J, McCowan LM: Maternal perception of fetal activity and late stillbirth risk: findings from the Auckland stillbirth study. Birth 2011, 38(4):311-316.

18. Froen JF, Tveit JV, Saastad E, Bordahl PE, Stray-Pedersen B, Heazell AE, Flenady V, Fretts RC: Management of decreased fetal movements. Semin Perinatol 2008, 32(4):307-311.

19. Gordon A, Raynes-Greenow CH, Bond D, Jones R, Rawlinson WL, Iwasenko J, Morris JM, Jeffery HE: Risk Factors for Late Pregnancy Stillbirth: The Sydney Stillbirth Study. In International Conference on Stillbirth, SIDS and Infant Survival: October 2012. Baltimore, MA; 2012:75.

20. Owusu JT, Anderson FJ, Coleman J, Oppong S, Seffah JD, Aikins A O'Brien LM: Association of maternal sleep practices with pre-eclampsia, low birth weight, and stillbirth among Ghanaian women. Int J Gynaecol Obstet 2013, 121(3):261-265.
21. Chappell LC, Smith GC: Should pregnant women sleep on their left? BMJ 2011, 342:d3659.

22. Froen JF, Cacciatore J, Fretts R, Flenady V: No need to worry about sleeping position in pregnancy - quite yet. BMJ 2011, http://www.bmj. com/rapid-response/2011/11/03/no-need-worry-about-sleeping-positionpregnancy-quite-yet.

23. Stacey T, Thompson JM, Mitchell EA, Ekeroma AJ, Zuccollo JM, McCowan LM: The Auckland Stillbirth study, a case-control study exploring modifiable risk factors for third trimester stillbirth: methods and rationale. Aust N Z J Obstet Gynaecol 2011, 51(1):3-8.

24. Breeze AC, Statham H, Hackett GA, Jessop FA, Lees CC: Attitudes to perinatal postmortem: parental views about research participation. J Med Ethics 2011, 37(6):364-367.

25. Warland J, Mitchell EA: A triple risk model for unexplained late stillbirth. BMC Pregnancy Childbirth 2014, 14(1):142.

26. Warrander LK, Batra G, Bernatavicius G, Greenwood SL, Dutton P, Jones RL, Sibley CP, Heazell AE: Maternal perception of reduced fetal movements is associated with altered placental structure and function. PLoS One 2012, 7(4):e34851

27. Winje BA, Roald B, Kristensen NP, Froen JF: Placental pathology in pregnancies with maternally perceived decreased fetal movement-a population-based nested case-cohort study. PLoS One 2012, 7(6):e39259.

28. Milsom I, Forssman $L$ : Factors influencing aortocaval compression in late pregnancy. Am J Obstet Gynecol 1984, 148(6):764-771.

29. Fleming PJ, Gillbert R, Azaz Y, Berry PJ, Rudd PT, Stewart A, Hall E: Interaction between bedding and sleeping position in the sudden infant death syndrome: a population based case-control study. BMJ 1990, 301(6743):85-89

30. Mitchell EA, Scragg R, Stewart AW, Becroft DM, Taylor BJ, Ford RP, Hassall IB, Barry DM, Allen EM, Roberts AP: Results from the first year of the New Zealand cot death study. N Z Med J 1991, 104(906):71-76.

31. Mitchell EA: Cot death: should the prone sleeping position be discouraged? J Paediatr Child Health 1991, 27(6):319-321.

32. Mitchell EA, Ford RP, Taylor BJ, Stewart AW, Becroft DM, Scragg R, Barry DM, Allen EM, Roberts AP, Hassall IB: Further evidence supporting a causal relationship between prone sleeping position and SIDS. J Paediatr Child Health 1992, 28(Suppl 1):S9-S12.

33. Wigfield RE, Fleming PJ, Berry PJ, Rudd PT, Golding J: Can the fall in Avon's sudden infant death rate be explained by changes in sleeping position? BMJ 1992, 304(6822):282-283.

34. Mitchell EA, Brunt JM, Everard C: Reduction in mortality from sudden infant death syndrome in New Zealand: 1986-92. Arch Dis Child 1994 70(4):291-294.

35. Dwyer T, Ponsonby AL, Blizzard L, Newman NM, Cochrane JA: The contribution of changes in the prevalence of prone sleeping position to the decline in sudden infant death syndrome in Tasmania. JAMA 1995, 273(10):783-789.

doi:10.1186/1471-2393-14-17

Cite this article as: Platts et al: The Midland and North of England Stillbirth Study (MiNESS). BMC Pregnancy and Childbirth 2014 14:171.

\section{Submit your next manuscript to BioMed Central and take full advantage of:}

- Convenient online submission

- Thorough peer review

- No space constraints or color figure charges

- Immediate publication on acceptance

- Inclusion in PubMed, CAS, Scopus and Google Scholar

- Research which is freely available for redistribution 